\title{
THE GREEK CATALOGUE OF ACTIVE FAULTS AND DATABASE OF SEISMOGENIC SOURCES
}

\author{
Pavlides S. ${ }^{1}$, Caputo R. ${ }^{2}$, Sboras S. ${ }^{2}$, Chatzipetros A. ${ }^{1}$, Papathanasiou G. ${ }^{1}$ \\ and Valkaniotis $\mathbf{S .}^{1}$ \\ ${ }^{1}$ Aristotle University of Thessaloniki, Department of Geology, Thessaloniki, Greece, \\ ${ }^{2}$ University of Ferrara, Department of Earth Sciences, 44122 Ferrara, Italy, \\ rcaputo@unife.it
}

\begin{abstract}
The new reasearch project to create the Greek Catalogue of Active Faults and Database of Seismogenic Sources has three major goals: (i) the systematic collection of all available information concerning neotectonic, active and capable faults as well as broader seismogenic volumes within the Aegean Region; the search will be mainly based on geological and geophysical data; (ii) the quantification of the principal seismotectonic parameters of the different sources and the associated degree of uncertainty; (iii) to supply an integrated view of potentially damaging seismogenic sources for a better assessment of the Seismic Hazard of Greece. The informatic framework of the database follows that used for the Italian Database of Individual Seismogenic Sources (DISS). In this paper we present the architecture of the new Database of Active faults of the broader Aegean Area relative to Greece, the progress made up to present and the following activities yet to be accomplished.
\end{abstract}

Key words: seismogenic fault, seismic hazard, Aegean.

\section{Introduction}

The Aegean Region is among the most tectonically active areas of the Mediterranean realm and has the highest seismicity both in terms of frequency of events and magnitudes. It is not always straightforward to correlate seismicity with the causative fault(s). This is mainly due to two reasons: firstly, several crustal sectors of the Aegean, where historical or instrumental epicentres are located, are affected by a dense fault population bearing evidences of recent activity but with badly defined seismotectonic behaviour. Secondly, large sectors of the broader Aegean Region is covered by the sea, therefore lacking crucial field and direct observations. In the latter case, the typical geological approaches are generally replaced with geophysical and seismological investigations (detailed bathymetry, seismic profiles, microseismicity, focal mechanisms, etc), which can be proved very useful.

The principal aim of this research is to create a catalogue as more complete as possible of Greek Active Faults and a Database of Seismogenic Sources within the Aegean Region. Indeed, such data collection, informatization and parametrization of the principal seismotectonic parameters is lacking for the area though it represents the very basics for any realistic seismic hazard assessment.

A first attempt to create a database of Greek seismogenic faults was performed in the frame of the European project FAUST (Faults as a seismological tool; 1998-2000), where ca. 50 sources have been included for the whole Aegean Region. In contrast, the most recent and most complete map of 
capable faults in Greece and the broader Aegean Region has been prepared by Pavlides et al. (2007).

Other attempts have been performed in the past, but all of them are lacking in both fault and data completeness. For example, simple map compilations cannot provide much information except the geographical location and a few geometrical characteristics of the faults, like length and dip direction. On the other hand, fault catalogues generally lack important additional data, like geometric, kinematic and seismological ones. In order to bypass the above problems and making the database a continuously updatable open-file, the choice of a GIS software environment was crucial. For our purposes we used the well tested, time-proof, worldwide acknowledged database structure and method proposed by the Istituto Nazionale di Geofisica e Volcanologia (INGV) for the Italian Database of Individual Seismogenic Sources (DISS), which represents the result of almost twenty years research experience of its Working Group (Valensise and Pantosti, 2001). The DISS uses many basic levels of data that can be either independent or directly related. Among the most important ones are the Individual Seismogenic Sources (ISS) and the Composite Seismogenic Sources (CSS) (see Basili et al., 2008, for a more detailed description of the software).

- "Individual Seismogenic Sources" (ISS) are obtained from geological and geophysical data and are characterized by a full set of geometric (strike, dip, length, width and depth), kinematic (rake) and seismological-palaeoseismological parameters (average displacement per event, magnitude, slip rate, return period) and by a rating of the associated uncertainties. ISSs are assumed to exhibit "characteristic" behaviour with respect to rupture length/width and expected mean and maximum magnitude. They are tested against worldwide databases for internal consistence in terms of length, width, average displacement and magnitude. This category of sources favours accuracy of the information supplied over completeness of the sources themselves. As such, they can be used for deterministic assessment of seismic hazard, for calculating earthquake and tsunami scenarios, and for tectonic and geodynamic investigations.

- "Composite Seismogenic Sources" (CSS) are still obtained from geological and geophysical data and characterized by geometric (strike, dip, width, depth) and kinematic (rake) parameters, but their length is more loosely defined and spans two or more Individual Sources. They are not assumed to be capable of a specific earthquake but their potential can be derived from existing earthquake catalogues. A CSS is essentially inferred on the basis of regional surface and subsurface geological data, that are exploited well beyond the simple identification of active faults or youthful tectonic features. Opposite to the previous case, this category of sources favours completeness of the record of potential earthquake sources over accuracy of source description. In conjunction with seismicity and modern strain data, CSSs can thus be used for regional probabilistic seismic hazard assessment and for investigating large-scale geodynamic processes.

Before preparing the catalogue and starting completing the database it is also useful to take into account the fault classification suggested by Pavlides et al. (2007). The major criteria are based on the degree of activity of the tectonic structures, thus allowing to distinguish six fault types:

1. Seismic faults: faults associated with significant earthquakes;

2. Holocene active faults: with documented displacement during the last $10 \mathrm{ka}$ and relatively high slip-rate;

3. Late Quaternary active faults: with documented displacement during the last $40 \mathrm{ka}$, corresponding to the maximum time interval possibly dated with the $14 \mathrm{C}$ method;

4. Quaternary active faults: with documented displacement during the Quaternary (2.6 Ma) and genrally characterized by a low-to-medium slip-rate;

5. Capable faults of uncertain age:with geometrical structure and kinematics favourably oriented 


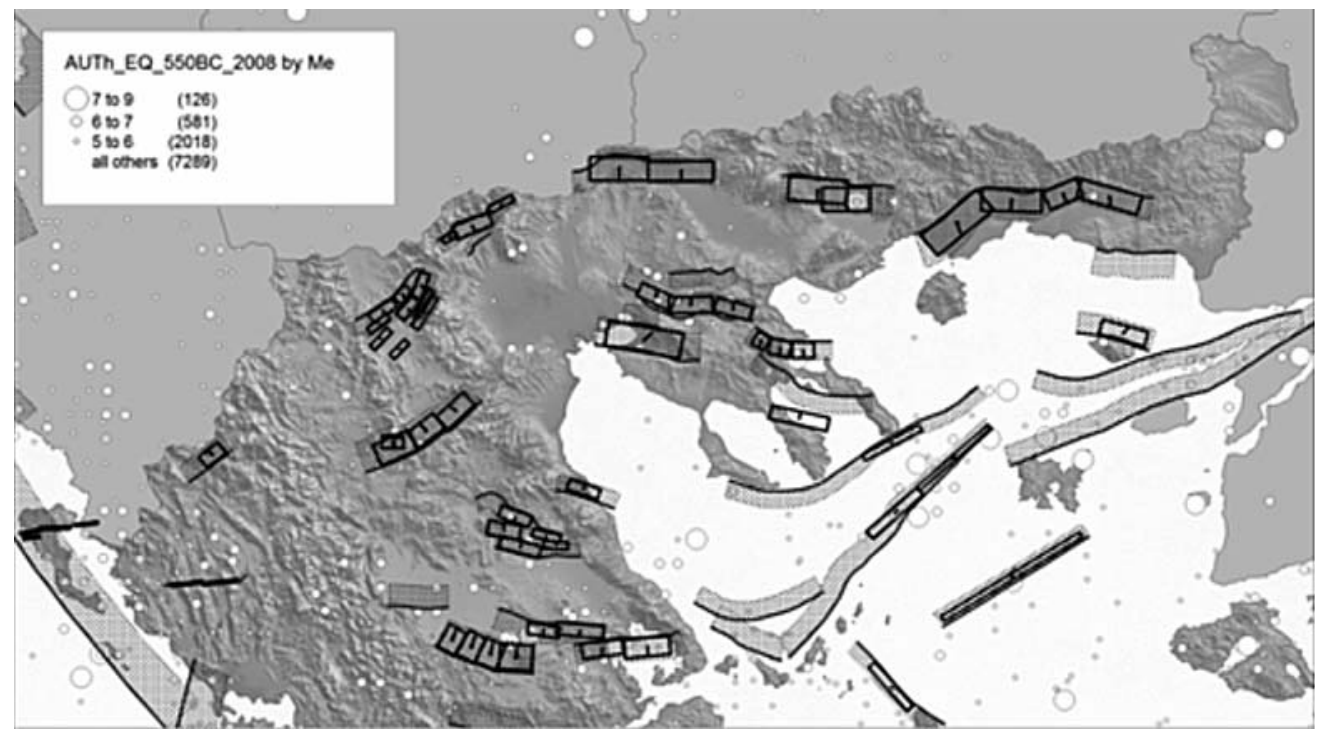

Fig. 1: The Greek Database of Active Faults for the North Aegean area.

in the frame of the present-day stress field, which could be possibly re-activated during a future earthquake;

6. Faults of uncertain activity: possibly inactive.

\section{Geological setting}

The broader Aegean Region is among the most tectonically active areas of the Mediterranean realm. The tectonic regime is rather complex producing earthquakes with many different orientations of nodal planes and a large variety of fault types both in terms of dimension and kinematics. Three are the dominating large-scale tectonic structures in the area. i) The Hellenic subduction zone, where the African plate is subducted underneath the Aegean; it is associated with a compressive stress field all along the arc. ii) The Inner Aegean region characterized by widespread, mainly N-S trending, crustal extension. iii) The North Aegean Trough (NAT) which represents a transtensional stress regime due to overlapping contribution of the western propagation of the purely strike-slip North Anatolian Fault and the Aegean extension. The combination of all previous tectonic processes produces an intense lithospheric fracturing and the formation of a large number of active faults.

\section{Methodology}

The procedure follows that proposed for DISS and it is based on MapInfo GIS software. It consists of two correlated software packages: the first is for managing the geometric and kinematic parameters of the ISSs, while the second one is the real core of the database providing the possibility of managing the compelte informatio of each ISS as well as controlling and managing the whole CSS attributes. The most common topographical background we use is a DEM obtained from the SRTM mission with 90x70 m pixel size, while when more detail is required, the 1:50000 scale topographic maps of HMGS or specific satellite imageries are used. For the offshore regions, bathymetric maps and DEMs are used from any available data source (e.g. the Marine Geoscience Data System MGDS). The whole dataset is referenced to the World Geographical System datum WGS84. 
The details about how faults are graphically represented in the database and what are the attributes of every information field can be found in the paper of Basili et al. (2008).

Regarding the qualitative part of the database, all available literature data for each seismogenic source are collected and investigated through a critical revision before entering the many information fields. Original investigations have been also carried out, and will be in the future, for structures with ambiguous or lacking data.

The data included in the database are separated in four major information levels. An interactive selection of a fault allows exploring the data in html formats. The first level of information is the "Source Info Summary" which includes all the parametrized information (geometric, kinematic and seismotectonic) of the fault and information about possibly associated earthquakes. Each of the information field is followed by a short comment concerning the origin of the data. The second level is the "Commentary" that contains comments, open questions and summaries of the considered literature. The third level is the "References", a list of all the related literature used to describe the particular fault. Each reference entry can be also linked with the appropriate electronic document, usually in pdf format. The "Pictures" level is the last one including figures and photographs relevant for the specific fault which can originate either from literature or from any personal collection.

The principal criteria for evaluating the seismogenic potential of a fault are briefly listed in the following.

Geological and morphotectonic features: surface morphology can be strongly affected by active tectonics and hence many such features can be recognized and characterized based on field work and laboratory analyses. Among the most important and commonly used morphotectonic features are fault scarps, triangular facets and the tilting of Quaternary sediments. The age and type of stratigraphic unit(s) affected by a fault scarp or a fault trace are crucial for estimating and constraining the last re-activation of a tectonic structure. The incision and displacement of very recent sediments is a highly important indicator of recent activity. At this regard, the contribution of palaeoseismological investigations is essential (e.g. McCalpin, 1996). A less explicit indicator is the occurrence of a free-face developed in bedrock. In this case, it is not the age of the affected rocks, usually Palaeozoic or Mesozoic in the Greek territory, to be indicative of a recent activity, but the freshness of the morphological feature as well as the geometry and texture of the fault scarp. Steep, sleek and polished surfaces indicate a young fault. Even difference in colour can be a guideline for estimating successive co-seismic re-activations by linear morphogenic events (e.g. Caputo et al., 2004; 2006). On the other hand, metamorphic rocks show poor evidence not only because of their greater erodibility, but also due to the internal fabric, like schistosity, that could generate by simple differential erosion morphological features similar to the tectonic ones. Additionally, with the aid of remote sensing analyses and dedicated software also many qualitative and quantitative morphometric parameters are generally considered, like the drainage pattern, stream orders, etc. (e.g. Goldsworthy and Jackson, 2000; Zovoili et al., 2004).

Seismic activity: it can occur either as localised major earthquakes (moderate to strong) or diffuse microseismicity (e.g. Hatzfeld et al., 1995; 2000; Kementzetzidou, 1996; Pavlides et al., 2007). It is useful to separate the major events as historical or instrumental ones. The former start with the 550 BC event (e.g. Guidoboni et al., 1994; Papazachos and Papazachou, 2003; Ambraseys, 2009) and can be used even for events from the $20^{\text {th }}$ century. The completeness and precision of events before the $19^{\text {th }}$ century is from poor to fair (Pavlides et al., 2007) making often difficult the correlation between earthquakes and causative fault. The instrumental period for the Aegean Region is less than 100 years, but it probably starts to be sufficiently accurate only after the 1970s when the Greek seis- 
mographic network was definitely improved. A typical example is the 1954, Sophades earthquake which was produced by a NNE-NE dipping fault according to geological investigations (Ambraseys and Jackson, 1990; Caputo, 1995; Pavlides, 1993) and not by a N-S up to NW-SE trending plane as suggested by the focal mechanism proposed by McKenzie (1972).

Also geophysical surveys based on different methodological approaches (electrical resistivity tomographies, ground penetrating radar, high-resolution seismic profiles, etc.) can provide useful information and constraints for characterizing an active fault (e.g. Caputo et al., 2003; Oliveto et al., 2004; Karastathis et al., 2007).

Regional geodynamic setting: the orientation of the fault plane with respect to the active stress field of the broader area is strong evidence (Pavlides et al., 2007). However, this approach could be somehow misleading in specific areas, since the tectonic regime is quite complex showing lateral variations or debated reconstructions by different authors. Areas like the northeastern Aegean or the Ionian Sea belong to this complex regime.

\section{Discussion}

Within the investigated area we have already recognized, characterized and parametrized almost 40 CSSs and about 60 ISSs. All ISSs show evidences of Late Pleistocene-Holocene activity andsometimes also the occurrence of past 'linear morphogenic earthquakes' (sensu Caputo, 2005) as inferred, for example, from palaeoseismological trenches, archaeoseismological investigations or detailed morphotectonic mapping. In some case, a moderate to strong earthquake has occurred in the last few decades, therefore allowing to investigate the re-activated fault with a great detail, based on a modern scientific approach, and especially generating a rich seismological information associated with the mainshock. In particular, recent instrumental data commonly provide crucial constraints about focal depth, magnitude, focal mechanism (i.e. strike, dip and rake) and aftershock distribution. This additional 'co-seismic' information is obviously not available for all the other geologicallybased seismogenic sources (ISSs) where no historical or instrumental earthquakes have been recorded. Accordingly, these faults represent a crucial test for the database and especially for its possible applications in seismic hazard assessment analyses. They have been independently investigated according to the two approaches, in one case the available 'co-seismic' constraints of the principal seismotectonic parameters have been ignored and mainly the cumulative effects of Late Quaternary morphogenic events have been considered; in the other case this additional co-seismic information has been included.

A first comparison shows an important mismatch between the two solutions and a deeper analysis on this difference will suggest a better strategy for the future.

The three following examples can help emphasizing the difference:

1. The Kozani CSS (Western Macedonia) was partly re-activated in 1995 by a Mw $=6.6$ event (Papazachos et al., 1995). Using 'only' all geological data, including stratigraphic, structural, morphotectonic and palaeoseismological ones (Pavlides et al., 1995; Mountrakis et al., 1998; Doutsos and Koukouvelas, 1998), three distinct fault segments, each potentially capable of generating moderate-to-strong events, can be recognized (Fig. 2a). In contrast, taking into account the 'co-seismic' information for constraining the principal seismotectonic parameters, a single major ISS can be defined (Fig. 2b). In this specific case, it is obvious that the western segment boundary, which was geologically inferred, was not strong enough to stop the propagation during the 1995 event that eventually re-activated two fault segments. On the other hand, 

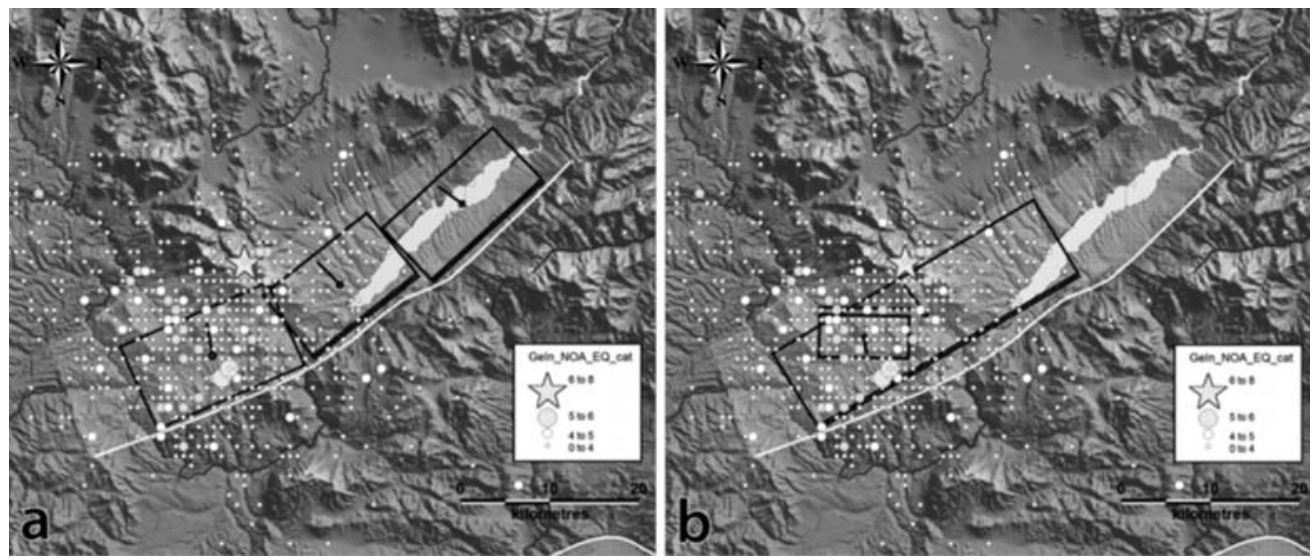

Fig. 2: The Kozani CSS (Western Macedonia) showing the three distinct fault segments, each capable of moderate-to-strong events, recognized based on all geological information relative to the cumulative evidence of Late Quaternary activity (a) and the seismogenic source as constrained considering the 'co-seismic' information associated with the $1995, \mathrm{Mw}=6.6$, earthquake (b). See text for further explanations.
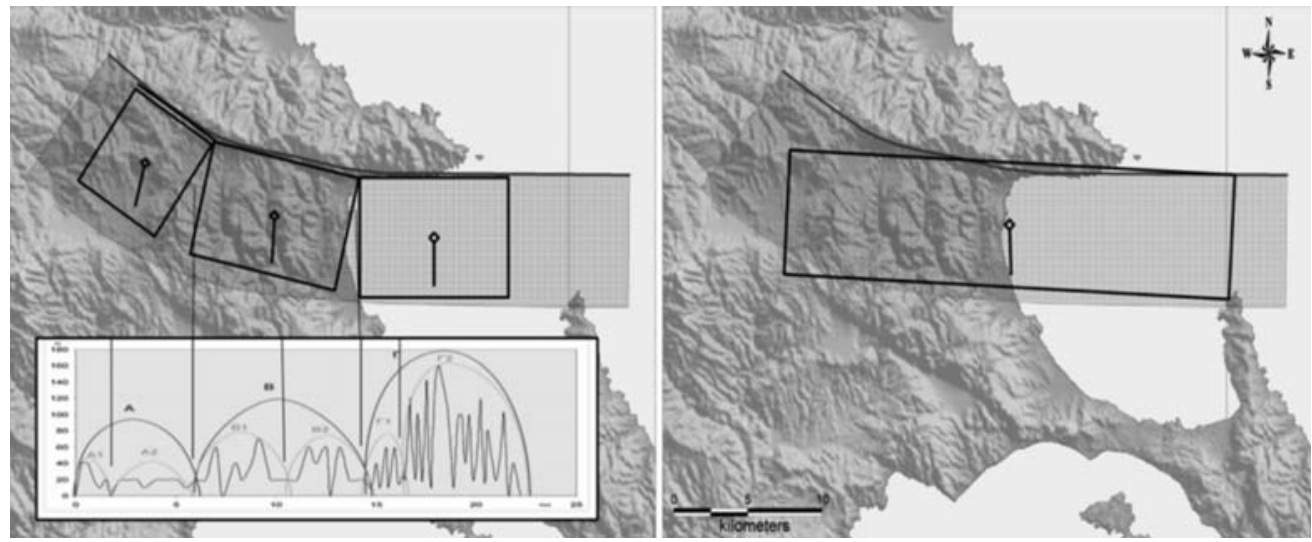

Fig. 3: The Varvara-Stratoni Fault (Chalkidiki peninsula, Central Macedonia) showing the three distinct fault segments, each capable of moderate(-to-strong) events, recognized based on all geological information relative to the cumulative evidence of Late Quaternary activity (a) and the seismogenic source as constrained considering the "coseismic' information associated with the 1932, Mw = 7.0, earthquake (b). See text for further explanations.

there is not apparent field evidence for why the third eastern segment did not rupture being separated by a similar segment boundary. It remains an open question whether the earthquake could have ruptured also the third segment or if this occurred in the past (or it will in the future), therefore causing an even more destructive larger magnitude event.

2. The second example is represented by the 1932 , Ierissos earthquake $(\mathrm{Mw}=7.0)$ that re-activated the Varvara-Stratoni Fault (Fig. 3). Also in this case, a detailed morphotectonic analysis (Michailidou et al., 2005) suggests the occurrence of three segments characterized by a different cumulative slip history and separated by angular boundaries. Accordingly, whether the geological evidence would suggest three capable faults, the co-seismic information indicates a unique major seismogenic source. 

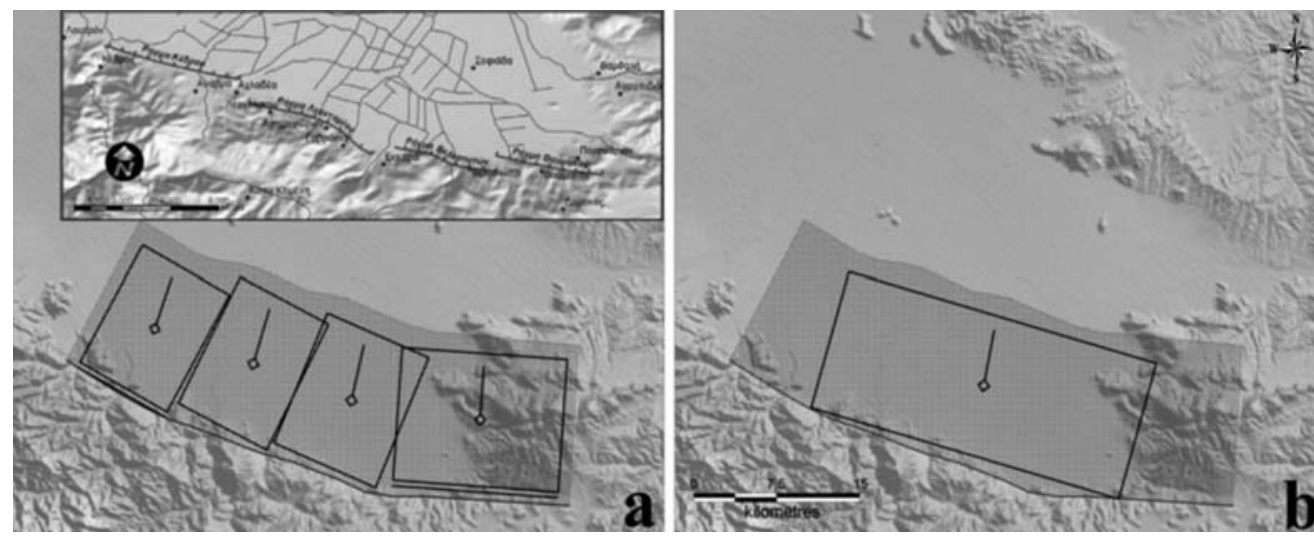

Fig. 4: (a) The Domokos CSS (Southern Thessaly) showing the four distinct fault segments, each capable of moderate-to-strong events, recognized based on all geological information relative to the cumulative evidence of Late Quaternary activity. (b) The seismogenic source as constrained considering the 'co-seismic' information associated with the $1954, \mathrm{Mw}=7.0$, earthquake. See text for further explanations.

3. The third case study refers to the 1954 , Sophades earthquake $(\mathrm{Mw}=7.0)$, when the Domokos CSS was partly activated (Fig. 4). The field observations documented by Papastamatiou and Mouyaris (1986), the geological and morphotectonic mapping by Caputo (1990; 1995) and Caputo and Pavlides (1993) and the detailed morphotectonic analysis of Valkaniotis (2005) suggest the occurrence of four left-stepping segments forming angular boundaries.

\section{Concluding remarks}

A large part of the Northern Aegean region has been studied, accomplishing the following targets:

The geographic location of about 40 Composite Seismogenic Sources (CSS) with (almost) complete parametrization ("Source Info Summary" information level) have been already prepared.

The geographic location and further analysis of 60 Individual Seismogenic Sources (ISS), with most of the information fields, comments, open questions, summaries, pictures and references have been completed.

The compilation of the database for the other sectors of the broader Aegean Region is in progress. Many of the faults under investigation and associated with specific historical or instrumental earthquakes (ISS) have been already recognized and mapped.

As far as other Aegean CSSs have geological and tectonic settings comparable to the Kozani and Ierissos case studies, showing the occurrence of geologically distinct fault segments, and reminding that the "characteristic behaviour" of the ISSs is an assumption, it is obvious the importance and need of more specific and careful investigations for improving the database.

\section{Acknowledgments}

Thanks to Roberto Basili and Gianluca Valensise (INGV, Rome) for providing the DISS software, their continuous assistance and discussions on seismogenic faults issues. Financial assistance provided by the Italian Ministery of University and Research to SS and RC is acknowledged. This is a contribution to the SHARE EU Project (Greek scientific resp. SP). 


\section{References}

Ambraseys, N., 2009. Earthquakes in the Mediterranean and Middle East: A Multidisciplinary Study of Seismicity up to 1900. Cambridge University Press, pp. 968.

Ambraseys, N.N. and Jackson, J.A., 1990. Seismicity and associated strain of central Greece between 1890 and 1988. Geophys. J. Int., 101, 663-708.

Basili, R., Valensise, G., Vannoli, P., Burrato, P., Fracassi, U., Mariano, S., Tiberti, M.M., Boschi, E., 2008. The database of individual seismogenic sources (DISS), version 3: summarizing 20 years of research on Italy's Earthquake Geology. Tectonophys., 453, 20-43.

Caputo, R., 1990. Geological and structural study of the recent and active brittle deformation of the Neogene-Quaternary basins of Thessaly (Greece). Scientific Annals, 12, Aristotle University of Thessaloniki, 2 vol., 5 encl., 252 pp., Thessaloniki.

Caputo, R., 1995. Inference of a seismic gap from geological data: Thessaly (Central Greece) as a case study. Ann. Geofisica, 38, 1-19.

Caputo, R., 2005. Ground effects of large morphogenic earthquakes. J. Geodyn., 40(2-3), 113-118.

Caputo, R. and Helly, B., 2005. The Holocene activity of the Rodia Fault, Central Greece. J. Geodyn., 40, 153-169, doi:10.1016/j.jog.2005.07.004

Caputo, R. and Pavlides, S., 1993. Late Cainozoic geodynamic evolution of Thessaly and surroundings (central-northern Greece). Tectonophysics, 223(3-4), 339-362.

Caputo, R., Piscitelli, S., Oliveto, A., Rizzo, E., Lapenna, V., 2003. The use of electrical resistivity tomography in Active Tectonic. Examples from the Tyrnavos Basin, Greece. J. Geodyn., 36, 1-2, 19-35.

Caputo, R., Helly, B., Pavlides, S. and Papadopoulos G., 2004. Palaeoseismological investigation of the Tyrnavos Fault (Thessaly, Central Greece). Tectonophysics, 394, 1-20, doi:10.1016/j.tecto.2004.07.047

Caputo, R., Monaco, C., Tortorici, L., 2006. Multi-seismic cycle deformation rates from Holocene normal fault scarps on Crete (Greece). Terra Nova, 18, 181-190, doi: 10.1111/j.1365-3121.2006.00678.x

Doutsos, T. and Koukouvelas, I., 1998. Fractal analysis of normal faults in northwestern Aegean area, Greece. J. Geodyn., 26, 197-216.

Goldsworthy, M. and Jackson, J., 2000. Active normal fault evolution in Greece revealed by geomorphology and drainage patterns. J. Geol. Soc. London, 157, 967-981.

Guidoboni, E., Comastri, A. and Traina, G., 1994. Catalogue of ancient earthquakes in the Mediterranean area up to $10^{\text {th }}$ century. ING-SGA, Bologna, $504 \mathrm{pp}$.

Hatzfeld, D., Kassaras, I., Panagiotopoulos, D., Amorese, D., Makropoulos, K., Karakaisis, G. and Coutant, O., 1995. Microseismicity and strain pattern in northwestern Greece. Tectonics, 14, 773-785.

Hatzfeld, D., Karakostas, V., Ziazia, M., Kassaras, I., Papadimitriou, E., Makropoulos, K., Voulgaris, N. and Papaioannou, C., 2000. Microseismicity and faulting geometry in the Gulf of Corinth (Greece). Geophys. J. Int., 141, 438-456.

Karastathis, V.K., Ganas, A., Makris, J., Papoulia, J., Dafnis, P., Gerolymatou, E. and Drakatos, G., 2007. The application of shallow seismic techniques in the study of active faults: The Atalanti normal fault, central Greece. J. Appl. Geophys., 62, 215-233.

Kementzetzidou, D., 1996. Étude sismotectonique du système Thessalie-îles Sporades (Grèce centrale). Ph.D. thesis, Université J. Fourier-Grenoble I, 151 pp., Grenoble.

McCalpin, J.P., (editor) 1996. Paleoseismology. Academic Press, 588 pp., San Diego.

McKenzie, D.P. 1972. Active tectonics of the Mediterranean Region. Geophys. J. Royal astron. Soc. London, 30, 109-185.

Michailidou, A., Chatzipetros, A. and Pavlides, S., 2005. Quantitative analysis -tectonic geomorfology 
indicators of the faults at the region of Stratoni - Varvara Gomati - M. Panagia in the Eastern Chalkidiki. Bull. Geol. Soc. Greece, 38, pp. 14-29.

Mountrakis, D., Pavlides, S., Zouros, N., Astaras, T. and Chatzipetros, A., 1998. Seismic fault geometry and kinematics of the 13 May 1995 Western Macedonia (Greece) earthquake. J. Geodyn., 26, 175-196.

Oliveto, A.N., Mucciarelli, M. and Caputo, R., 2004. HVSR prospections in multi-layered environments: an example from the Tyrnavos Basin (Greece). J. Seismol., 8, 395-406.

Papastamatiou, D. and Mouyaris, N., 1986. The earthquake of April 30, 1954, in Sophades (Central Greece). Geophys. J.R. astron. Soc., 87, 885-895.

Papazachos, B. and Papazachou, C., 2003. The earthquakes of Greece, Editions ZITI, Thessaloniki, 304.

Papazachos, B.C., Panagiotopoulos, D.G., Scordilis, E.M., Karakaisis, G.F., Papaioannou, Ch.A., Karakostas, B.G., Papadimitriou, E.E., Kiratzi, A.A., Hatzidimitriou, P.M., Leventakis, G.N., Voidomatis, Ph.S., Peftitselis, K.J. and Tsapanos, T.M., 1995. Focal properties of the 13th May 1995 large (Ms = 6.6) Earthquake in the Kozani area (North Greece), XV Congr. Carpatho-Balkan Geological Association, September 17-20, 1995, Athens, Greece, Proceedings, 96-106.

Pavlides, S. 1993. Active faulting in multi-fractured seismogenic areas; examples from Greece. Z. Geomorph. N.F., 94, 57-72.

Pavlides, S.B, Zouros, N.C, Chatzipetros, A.A., Kostopoulos. D.S. and Mountrakis, D.M., 1995. The 13 May 1995 western Macedonia, Greece (Kozani Grevena) earthquake; preliminary results, Terra Nova, 7, 544-549.

Pavlides, S.B., Valkaniotis, S. and Chatzipetros, A., 2007. Seismically capable faults in Greece and their use in seismic hazard assessment. 4th Int. Conf. Earthq. Geotech. Eng., June 25-28, 2007, Thessaloniki, Proceedings, paper n. 1609.

Valensise, G. and Pantosti, D., (Eds) 2001. Database of potential sources for earthquakes larger than M 5.5 in Italy. Ann. Geofisica, 44, 797-807.

Valkaniotis, S., 2005. Active faults investigation of Western Thessaly. MSc. thesis, Aristotle University of Thessaloniki, pp. 118 [in Greek].

Zovoili, E., Konstantinidi, E. and Koukouvelas, I.K., 2004. Tectonic geomorphology of escarpments: the cases of Kompotades and Nea Anchialos faults. Bull. Geol. Soc. Greece, XXXVI, 1716-1725. 